\title{
How Are the Arts Faring? Trend Analysis of Students' Enrolment in the Faculty of Arts, University of Cape Coast
}

\author{
Juliana Audria Dankwa \\ Centre for International Education (CIE) \\ University of Cape Coast, Ghana
}

\begin{abstract}
The Faculty of Arts of the University of Cape Coast began as the Department of Arts in March 1962. The Faculty has developed to become a vibrant and one of the largest faculties in terms of the number of departments. However, current enrolment figures and documents available in the University suggest dwindling enrolment figures. Using a content analysis approach, this case study examines the trend in student enrolment in the Faculty of Arts. The results indicate that, apart from the recently introduced Bachelor of Arts (BA) Communication Studies, the other programmes in the Faculty have witnessed a decline in students' application and enrolment over the last five years. Reasons accounting for this consistent decline include the process of admissions, offer of programmes and courses, students' choices, and the progression of students from one level to the other. It is recommended that programmes in the Faculty should be reviewed to meet the current needs of society to attract more applicants.
\end{abstract}

Keywords: Liberal Arts Programmes, Faculty of Arts, student enrolment, trend analysis

DOI: $10.7176 / \mathrm{PPAR} / 11-2-06$

Publication date:March $31^{\text {st }} 2021$

\section{Introduction}

It is reported that generally, the liberal arts education is receiving low patronage in all public Ghanaian universities as compared to the sciences (Republic of Ghana, 2002). Declining student enrolments, and misconceptions about graduate's employment prospects have created a false-crisis narrative (Hunt, 2016). For instance, with the discovery of Oil and Gas, in the Western Region of Ghana, more parents and the Government of Ghana are encouraging students to pursue science-related programmes (Republic of Ghana, 2002). Many students and their parents now seek a clear and early connection between undergraduate experience and employment. Parents and their wards argue that training to be a doctor leads to a job as a doctor, whereas a degree in history or English can lead to many different career opportunities and a lifetime of evolving careers (Hunt, 2016). Following the increasing number of graduate unemployment, students, parents, and educators are questioning paths of study that do not have a direct line to a specific job (Hunt, 2016).

The discussion about the usefulness of the liberal arts programmes spans across different civilizations. Nevertheless, recent financial and social pressures have placed the survival of the liberal arts at even greater risk. There seems to be a decline in people seeking liberal arts education (Logan \& Curry, 2015). Many more countries are concentrating on science, technology, engineering, and mathematics (STEM). The reason is not farfetched as many countries expect its citizens to be energized to help solve some of today's global challenges such as climate change and other environmental and health related issues (Logan \& Curry, 2015). Ghana is no exception to this global change. Successive governments have channeled a lot of resources towards STEM education. In most universities in Ghana, scholarships are geared towards students who find themselves in the STEM programmes (Republic of Ghana, 2002). Examples of such scholarships are the Ghana National Petroleum Corporation (GNPC) scholarship which is awarded to students in the science-related programmes and the Ghana Education Trust Fund (Get FUND) which also commits most of its share to people in the sciences.

In the University of Cape Coast, premium is placed on programmes such as medicine, optometry, physician assistant and other science-related courses (Vice-Chancellor's speech to the $50^{\text {th }}$ Congregation, 2017). It is therefore not surprising that the management is earnestly pushing for the running of the pharmacy programme. Provision for these programmes seems to receive massive support from management in the name of the institutional image to the detriment of the Arts. During student-staff consultative meetings, students in the performing arts complain about lack of equipment and studio for performances.

The Faculty of Arts has sent several memoranda to central administration on the need to equip these lessendowed departments to be able to function well. Several memoranda written by the individual departments and faculty have not yielded expected results. A visit to the School of Medical Sciences (SMS) laboratory depicts the state of art equipment. The same applies to the Department of Optometry where with the support of management, the department's laboratory has been equipped with modern equipment for effective teaching and learning.

Equally, the Departments of Communication, Film and Theatre Studies need laboratories for practice. These departments have been in existence for over ten years before the SMS came into being. The question is, what happens to the practical components of these programmes? We cannot all imagine a medical student 
without practical practice or laboratory for practice. Policy makers will think it is absurd, so will commit resources to see to its realization. In the case of the Arts, it comes across as a normal phenomenon, with central administration expecting the individual department to support itself with the meagre academic facility user fee (AFUF). A look at the students' enrolment statistics shows that some departments cannot support themselves solely with the AFUF. The Departments of Communication, Theatre and Film Studies need equipment and logistics such as well-equipped studio, cameras, and machines for recordings. These equipment are capital intensive and their meagre AFUF cannot support the purchase of these equipment.

The Department of Music and Dance has been supported with a building facility. Apart from the structure that has been provided by the University, the Department will have to look for money to equip the place. The Department is one of the less-endowed units: its major source of income is mainly AFUF. With the few numbers who enroll onto the music programme, it is difficult for the Department to adequately equip its studio. The Department of Music comes across as a department that is remembered when it comes to UCC functions such as congregations, matriculations, and inaugural lectures. The above issues are found to be inimical if not addressed and could result in the collapse of some departments. These are some of the challenges that the Faculty of Arts faces. This perfectly fits into the global issues facing the liberal arts (Hunt, 2016).

\section{Background}

One of the prevalent issues of first-year students of the Faculty of Arts is the problem of change of programme and change of course combinations. Available records gathered from students file and admission records show that about $26 \%$ of students who gain admission to the Faculty of Arts report to their academic counsellors and Heads of Department about a change of a particular course assigned to them or a total change of programme. When freshmen and women report to UCC campus, the first week is devoted to helping them adjust to their new environment. Several orientation sessions are conducted during this one week to help students understand the university system. Subsequently, faculty/departments orientation is held for students. The purpose of this orientation is to help new students meet faculty, explain faculty and department requirements to students and importantly, give students insight into the courses and programmes they have been admitted to study in the university. It is after the faculty/department orientation that some students understand the programmes they have chosen and their implications. After students gain insight into their programmes, some students after reflection, taking their interests and abilities into consideration, may opt for other programmes instead of the programmes they have originally applied for. This change of programme is a common issue at the Faculty of Arts. Each year, departments receive complaints from students who for some reasons would like to change a programme or a course. One out of fifteen students from the various departments each year expresses interest in a change of programme or a course. Evidence is seen from letters from the various heads of department putting across a student's petition of change of course. Although some students have genuine reasons to want to change their courses such as lack of interest, issue of study leave with pay, uninformed decision, lack of information on the programme or the courses chosen, some would also like to change their courses due to peer influence, fulfilling parents' wishes and the commonest of it which is, negative information about some lecturers of a particular course.

Data gathered from fresh students of the 2016/2017 academic year of the College of Humanities and Legal Studies showed that most students get to know the contents of the programmes they have chosen after the students have received orientation from their respective departments. Evidence from files and the Directorate of Academic Affairs (DAA) indicate that some courses are assigned to students arbitrarily. This is because the BA Arts programme has some courses that are not pursued by students at the Senior High School (SHS) level. Some of these are African Studies, Theatre and Film Studies, Dance, Linguistics and Classics and Philosophy. As a result, students are assigned to these courses based on the results presented by the applicants.

However, report from the examination results show that a substantial number of students who during the orientation period complained of their courses trail some courses. Some students after persistent complaints abandon the programme altogether. Reports gathered from students revealed that, these affected students who fall out from the programmes end up enrolling in some of the university's mentoring institutions. Some students on the other hand, although may have issues with the course combinations, do not report or seek further counselling. Data gathered from Academic counsellors from the Faculty showed that some students wait until the end of the year or semester when they are trailing or on the verge of withdrawal before they report their lack of interest or inability in a particular course. When this happens, the change of course or programme is virtually impossible.

At a meeting of Heads of Department of the Faculty of Arts, members expressed concern about the dwindling number of students in the various programmes. One of the solutions provided by members was to visit Senior High Schools (SHS) to market the programmes of the Faculty. Although the solution sounded laudable, this may not have a significant effect on the number of enrolments. In 2016/2017 academic year, the Faculty of Social Sciences visited some selected schools in the Western Region of Ghana. The visit did not have any impact 
on the enrolment statistics of the 2018/2019 and the 2019/2020 students' enrolment in the Faculty. Interactions with the students revealed that most students were aware of programmes ran by most universities in Ghana. Further responses showed that students obtain the information from the universities' website and friends, alumni, and current students and about $38 \%$ of the students stated that they preferred career- oriented programmes.

In 2018, some students of the Faculty of Educational Foundations also organized a career guidance programme for SHS students in selected schools in the Cape Coast metropolis. A survey conducted among these students revealed that most students $(87 \%)$ preferred programmes that can guarantee them jobs as professionals. This may explain why the liberal arts have received low patronage for its programmes and a shoot up of the selection quota for the career-oriented programmes.

The broadsheet for the selection of applicants of the Faculty of Humanities and Social Sciences Education revealed that in 2018/2019 academic year, 251 students applied to study the Bachelor of Education (B.Ed. Arts) programme with varied options in the Department of Arts Education as against 228 applicants for the BA Arts programme. Out of the 251 B.Ed. Arts applicants, 199 students were admitted. The 2019/2020 academic year broadsheet also showed that 372 students applied to the B. Ed Arts programme as against 148 applicants for the BA Arts programme. Out of the 372 applicants, 238 were admitted. In both years, the remaining applicants were transferred to the various programmes in the Faculty of Arts. The same trend goes for the Bachelor of Arts (Social Science) programme and that of Bachelor of Education (Social Science).

From 2014 to 2016, the quota for qualified applicants into the Faculty of Arts has been 600. From 2017 to date, the quota provided by DAA has reduced to 500 while some faculties/ schools such as: Medical School, Law, Nursing, Business and the Faculty of Humanities and Social Sciences Education have maintained their quota or have had an increase in their quota. A reason for a drop in the quota of the Faculty of Arts is that, consistently, the Faculty has not adequately exhausted its quota provided by DAA.

For the past 3- 4 years, the quota for the Faculty of Humanities and Social Sciences Education has been 600 . The Faculty has two departments. This means that the Faculty is supposed to divide the quota of 600 to its two departments. The number of applicants into the Faculty has always been more than the quota given. Therefore, each year, the Faculties of Arts and Social Sciences in the College of Humanities and Legal Studies admit the excess of students who applied to the Faculty of Humanities and Social Sciences Education of the College of Education Studies. The notion is that applicants tend to prefer education programmes to the mere Arts programmes. This is corroborated with evidence from the Faculty of Humanities and Social Sciences Education of the College of Education Studies where more students subscribe to their programmes. It also confirms the survey conducted by the Faculty of Social Sciences where about $62 \%$ of the students surveyed stated their preference for career- oriented programmes.

It has therefore become necessary to examine students' enrolment pattern from 2015 to 2019 as a way of providing ecological data to inform the Faculty of Arts to review its programmes. In line with the study's main purpose, the following research questions were formulated to guide the data collection and analyses:

1. What are the enrolment trends in the Faculty of Arts from 2015-2019?

2. What is the status of students' enrolment in the various departments and Centre?

3. What is the post admission challenges students face in the various programmes?

\section{Methods}

\subsection{Design and data collection}

This study employed a case study design to collect secondary data from the Faculty of Arts, College of Humanities and Legal Studies of the University of Cape Coast. Broadsheets from the DAA on students' applications, files containing admission lists, minutes on admissions covering the period under review (i.e., from 2015 to 2019) were collected, coded and analyzed using the case study approach proposed by Yin (2009). The first-three cases, thus, the 2015-2017 data on students' application, admissions, and enrolment figures were obtained from files available at the Faculty. The documents on the 2018 and 2019 figures were taken from the directorate's database.

\subsection{Results and Discussion}

\subsubsection{Enrolment trends in the Faculty of Arts from 2015- 2019}

The Faculty currently offers eight (8) programmes at the undergraduate level. These programmes include: Bachelor of Arts (African Studies, Communication Studies, Dance, Film Studies, Linguistics, Theatre Studies, and Bachelor of Arts (Varied Fields: English, French, History, Ghanaian Language, Religion and Human Values, Classics and Philosophy).

The results indicate that apart from the BA Communication programme which has seen a steady increment in the enrolment of students, all the other programmes have witnessed consistent decrease in student enrollment. The following programmes have consistently performed abysmally: Dance, Music, Theatre and Film Studies, consistently receiving less than ten students each year for the last three years. In 2017, less than ten students 
applied to the BA Linguistics programme. Due to that reason, applicants were assigned different programmes.

Table 1 indicates that in the 2017/2018 academic year, 46 students applied to study BA African Studies, but 21 students accepted the offer to pursue the programme. In 2018/2019, 21 students applied; 14 students accepted the offer. We note that, in the same vein, for BA Communication Studies, in 2017/2018, 199 students applied to the programme, and 207 students enrolled. The 2018/2019 academic year had 131 applicants with 131 enrolling, indicating $100 \%$ enrolment. We cannot conclude that this is a perfect score because we must make room for protocol admissions and transfer of applicants from one programme into another. Although the Faculty received a handful of applications for the BA Dance, Theatre, Film and Music programmes, enrolment into the programmes by the applicants have not been encouraging. For the last five years, the BA Dance programme has recorded zero per cent of students' enrolment.

Figure 1 shows the trend in number of students who applied and were admitted to study in the various programmes in the Faculty from 2015 to 2019 as per the broadsheets provided by the Directorate of Academic Affairs (DAA).

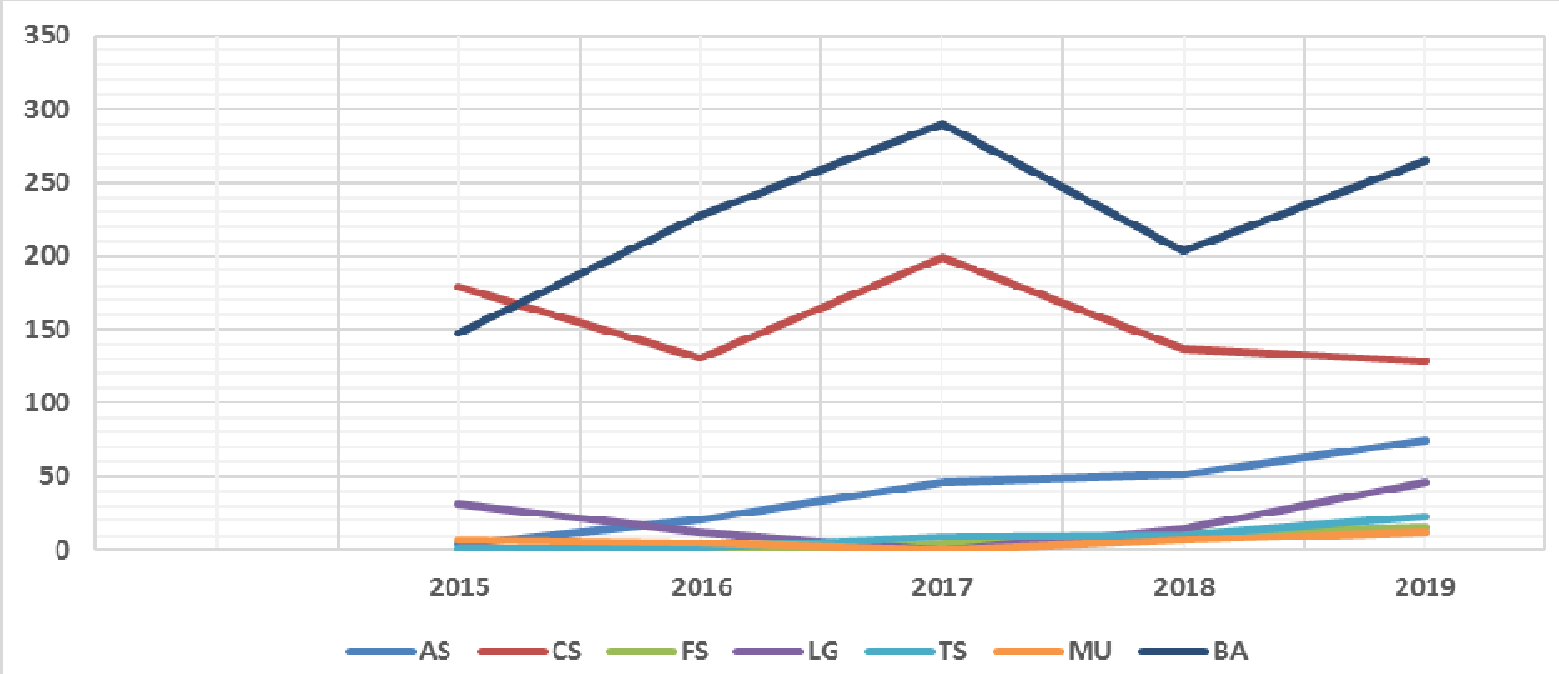

AS = African Studies, CS = Communication Studies, FS $=$ Film Studies, LG $=$ Linguistics, TS $=$ Theater Studies, MU = Music, BA = BA Arts (varied programmes). Source: MIS (2019)

Figure 1: Students' application statistics (2015-2019)

Figure 1 reveals that the BA Dance is the least preferred programme by applicants. The Figure shows that from 2015 to 2019, only six students applied to the programme. For the 2017/2018 and 2018/2019 academic years, no application was received. Film Studies and Music have both managed 30 applicants over the last 5 years, with Film Studies recording zero number of applicants for the 2017/2018 and 2018/2019 academic years.

Theatre Studies, on the other hand, has seen a sharp decrease in the number of applicants. In 2015/2016 academic year, the programme recorded its highest number of applicants (23) but reduced significantly to 2 applicants in 2017/2018 and one applicant for the 2019/2020 academic year.

The Faculty's flagship programme appears to be the BA Communication Studies programme which has seen quite a steady improvement over the years. The programme made significant increase from 128 applicants in the 2015/2016 academic year to 199 applicants in the 2016/2017 academic year. The number of applicants, however, dropped to 131 in the 2017/2018 and increased to 179 in the 2019/2020 academic year. The BA Linguistics programme, on the other hand, has been fluctuating, having a total number of 103 students since the last five years with no intake in 2016/2017 academic year. It recorded 12 applicants in 2017/2018 but has seen an improvement in the 2019/2020 applications with 31 applicants.

The oldest programme of the Faculty is the BA Arts programme. This programme encompasses all the programmes ran at the Faculty of Arts. This programme has also seen a systematic reduction in students' enrolment. In 2015/2016 academic year, 265 applications were received. This number dropped to 204 in the following academic year. It however, made a significant increase in 2017/2018, receiving 290 applications. It again reduced in 2018/2019 and 2019/2020 academic years receiving 228 and 148 applications, respectively. The total number of students' enrolment shows that, for the past 5 years, the Faculty of Arts has not been able to meet its quota. From 2015/2016 to 2016/2017 academic years, the quota allotted to the Faculty was 600 . However, in 2015/2016, 567 students applied to represent 94\%, indicating a deficit of 6\%. Similarly, in $2016 / 2017,435$ students applied to represent $72 \%$ with a shortfall of $28 \%$. Applications received for $2017 / 2018$ were $550(92 \%)$ with an outstanding difference of $8 \%$.

The quota for the Faculty reduced from 600 to 500 students representing a $10 \%$ reduction in student 
enrolment allocation. Despite the reduction in the quota, the Faculty could not meet its required quota. This is how the Faculty faired. In 2018/2019, 399 (80\%) students applied while 370 (74\%) students applied in 2019/2020. Overall, out of the 2,800 expected applications, the Faculty received 2,321 (83\%) applications.

Figure 2 depicts a trend of the number of students (actuals) who enrolled unto the various programmes in the Faculty from 2015/2016 to 2019/2020 academic year.

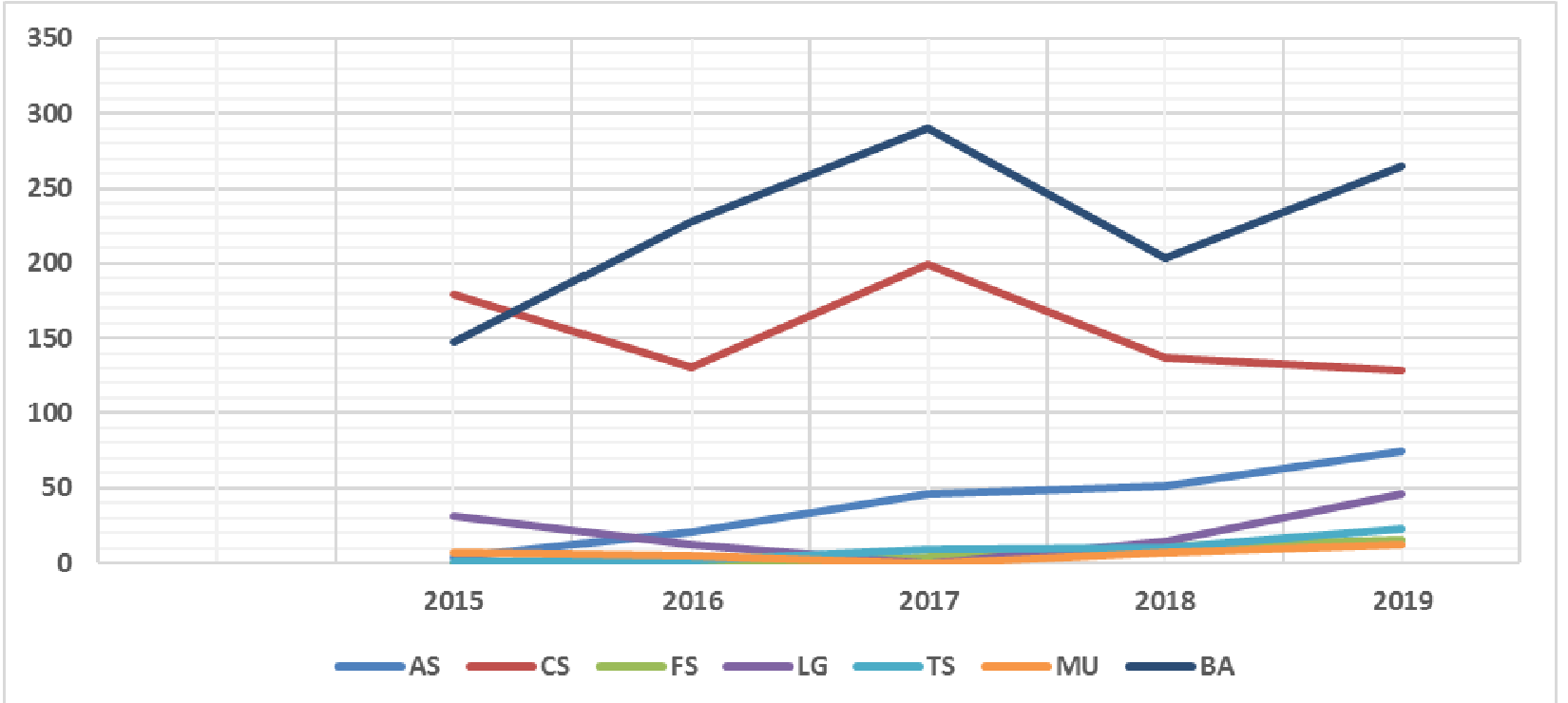

AS = African Studies, CS = Communication Studies, FS = Film Studies, LG $=$ Linguistics, TS $=$ Theater Studies, MU = Music, BA = BA Arts (varied programmes). Source: MIS (2019).

Figure 2: Actual enrolment of students into various programmes (2015 to 2019)

Figure 2 shows that BA Dance recorded zero number of students from 2015 to 2019. This implies that although from 2015 to 2019, 6 students had applied to study BA Dance, they did not accept the offer. In 2015/2016, 75 students applied to study African studies, 42 students accepted the offer representing 56\%. Similarly, in 2016/2017, the Centre had 51 offers but 28 (55\%) of them enrolled. The Centre garnered $21(46 \%)$ and $14(67 \%)$ students for the 2017/2018 and 2018/2019 academic years, respectively.

BA Communication Studies had 128 students applying in 2015/2016 academic year, out of which 96 (75\%) students enrolled. The enrolment saw a significant increase in 2017/2018 (100\%) and 2018/2019 (100\%) academic years. Consistently, throughout the years, the department of Communication Studies has not been able to admit all the students who apply to study the programme. A proportion of the students are enrolled unto other programmes in the Faculty.

Lastly, in 2015/2016 and 2016/2017 academic years, the BA Arts programme enrolled 183 and 185 students, respectively. It, however, saw a significant increase in its enrolment in 2017/2018, enrolling 267. In 2018/2019, the students' enrolment dropped to 216 students. There was, however, a significant increase to 300 students in $2018 / 2019$ academic year. It is worth noting that these enrolments include leftover applications from the BA Communication Studies programme and transfer of students from the Department of Arts Education of the College of Education Studies.

\subsubsection{Post Admission Challenges}

The third research question sought to look at the post admission challenges faced by the various departments and students. A student applying to study in the Faculty of Arts is guided by the UCC prospectus. The prospectus captures all the programmes ran by the Faculty. Apart from the specific degree programmes which include, African studies, Communication studies, Theatre and Film Studies, Linguistics and Music and Dance, some students are admitted into a general Bachelor of Arts programme. The following combinations are some examples that make up the Bachelor of Arts programme with varied options: French, English, African Studies, Ghanaian Language, Classics and Philosophy, Religious Studies, Theatre, Film, Music, History and Linguistics.

The permutations for course combinations are done depending on the results provided by the students on the broadsheet. This means that applicants are given the various combinations depending on the West Africa Examination School Certificates/Senior Secondary Certificate Examination (WASCE/SSCE) results. For example, a student who read English Literature, Religious Studies, History and Ghanaian Language may be given the following combinations depending on the grades of the applicant: English Language, History and Ghanaian Language or Linguistics, Ghanaian Language and Religion or Ghanaian Language, Classics and Philosophy and English.

Again, a student with a Social Science background of Economics, Geography and Elective Mathematics 
may apply to the BA Arts programme. In such an instance, the student may be offered African Studies as one of his/her electives. Again, a student with a good grade in the elective subject Government is given Classics and Philosophy as one of his or her electives. Applicants with a background in the Visual Arts are offered courses in Theatre and Film studies. However, documentary analysis and evidence from the admission broad sheets show students who do not accept the offer are students who have been assigned programmes which hitherto are not pursued at the SHS level.

\section{Conclusion}

The purpose of the review was to look at the enrolment trends in the Faculty of Arts. Data collected for this study showed that the programmes in the Faculty, except Communication Studies, have consistently recorded a low number of Post (WASSCE/SSCE) students applying to enroll in the various programmes in the Faculty. Again, in recent years, undergraduates have sensed that traditional liberal education may not by itself be sufficient preparation for the adult world, they therefore prefer career-oriented jobs.

\section{Recommendations}

Based on the findings and the conclusions drawn, the following recommendations are proffered to help stem the downward trend of student enrollment in the Faculty of Arts:

1. The admission board should review the way courses are given to students arbitrarily. The Faculty should put mechanisms in place to allow students to choose courses they prefer. The 2. DAA should make room for students who for some reasons would like to change their courses especially if the course is ran in the Faculty.

2. There should be more focus on the less-endowed departments. Without these departments, there would be no Faculty of Arts.

3. Dance should be infused into either music, film, or theatre studies. UCC is not known for these programmes traditionally. University of Ghana, and University of Education, Winneba are the home for these programmes. However, restrictions to only SHS graduates who offered General Arts into the Faculty of Arts need to be checked. Placement must be done based on the ability and interest of the applicant. For example, a science student who has interest in music should be admitted provided the student meets the general university admission requirements.

4. The students are calling for a diversification of liberal arts education which is career oriented. It is therefore important for the Faculty to revamp its course contents to suit modern demands.

\section{References}

1. Hunt, S. J. (2016). The life courses: A sociological introduction. Macmillan International Higher Education.

2. Logan, J., \& Curry, J. (2015). A liberal arts education: Global trends and challenges. Christian Higher Education, 14(1-2), 66-79.

3. MIS (2019) Data on Students Enrolment Statistic, University of Coast

4. Republic of Ghana. (2002). Meeting the challenges of education in the twenty-first century: A report of

the President's committee on review of education reforms in Ghana. Accra: Adwinsa Publications

5. Vice Chancellor's Annual Report (2017). University of Cape Coast, Cape Coast.

6. Yin, R. K. (2009). Case study research: Design and methods. Thousand Oaks, CA: Sage. 